\section{Cumulation and reversal with prolonged infusions of atracurium and vecuronium}

Raymond J. Martineau MD, Bernard St.-Jean MD, John B. Kitts MD, Michael C. Curran MD, Patricia Lindsay RN, Kathryn A. Hull RN, Donald R. Miller MD
A randomized, double-blind study was undertaken to compare the tendencies for cumulation, and reversal characteristics of atracurium (ATR) and vecuronium (VEC) when administered by continuous infusion for long surgical procedures under balanced anaesthesia. Eligible subjects were between 50 and 75 yr of age and were free of neuromuscular disease. Patients in the ATR group $(n=25$ ) received a loading dose of atracurium 0.25 $m g \cdot \mathrm{kg}^{-1}$, followed by an infusion initially set at 5.0 $\mu \mathrm{g} \cdot \mathrm{kg}^{-1} \cdot \mathrm{min}^{-1}$. In the VEC group $(n=25)$ patients received $a$ loading dose of vecuronium $0.05 \mathrm{mg} \cdot \mathrm{kg}^{-1}$, followed by an infusion at $1.0 \mu \mathrm{g} \cdot \mathrm{kg}^{-1} \cdot \mathrm{min}^{-1}$. During surgery, the infusions of both ATR and VEC were titrated in increments or decrements of $12.5 \%$ to maintain first witch $\left(T_{1}\right)$ suppression of $90-95 \%$. Neuromuscular block was measured by recording the integrated evoked electromyographic response (EMG) of the first dorsal interosseous muscle in response to supramaximal TOF stimulion the ulnar nerve. The durations of infusion were similar for the two groups (164 \pm 42 and $183 \pm 67 \mathrm{~min}$ for ATR and VEC, respectively). The infusion rates of $A T R$ (mean $\pm S D$ ) remained between $4.0 \pm 0.7$ and $5.0 \pm 1.0 \mu \mathrm{g} \cdot \mathrm{kg}^{-1} \cdot \mathrm{min}^{-1}$ throughout the

\section{Key words}

ANAESTHETIC TECHNIQUES: continuous infusions; MEASUREMENT TECHNIQUES: electromyography; NEUROMUSCULAR BLOCKING DRUGS: atracurium, vecuronium.

From the Departments of Anaesthesia, Ottawa General Hospital and Ottawa Civic Hospital, and the University of Ottawa.

Presented at the Annual Meeting of The Canadian Anaesthetists' Society, Toronto, Ontario, June 5-9, 1992.

Supported by a Research Grant from Burroughs-Wellcome Inc.

Address correspondence to: Dr. Donald R. Miller, Department of Anaesthesia, Ottawa General Hospital, 501 Smyth Road, Ottawa, Ontario, K1H 8L6.

Accepted for publication 15th May, 1992. study period. In contrast, a progressive decrease $(P<0.05)$ in the infusion rate of VEC, from 1.0 to $0.47 \pm 0.13$ $\mu \mathrm{g} \cdot \mathrm{kg}^{-1} \cdot \mathrm{min}^{-1}$, was observed during the study period. The number of adjustments required to maintain 90-95\% $T_{1}$ suppression decreased between the second and fourth hours of administration, but were similar at corresponding times when comparing the two groups. The times to recover to a TOF ratio $>70 \%$ following reversal with neostigmine $40 \mu \mathrm{g} \cdot \mathrm{kg}^{-1}$ and atropine $15 \mu \mathrm{g} \cdot \mathrm{kg}^{-1}$ were also similar for the two groups (13.4 \pm 4.9 and $14.4 \pm 8.0 \mathrm{~min}$ for $A T R$ and VEC, respectively). We conclude that a constant infusion of vecuronium adjusted to maintain $T_{1}$ suppression of $90-95 \%$ results in cumulation which is manifest after the second hour of administration. In contrast, atracurium shows little tendency for cumulation during infusions lasting between two and five hours. When titrated according to individual patient response, infusions of both atracurium and vecuronium are characterized by their ease of administration and their ability to be readily reversed with appropriate doses of neostigmine.

Cette étude à double insu compare les propriétés cumulatives et la reversibilité de l'atracurium (ATR) et du vécuronium (VEC) administrés en perfusion continue pour des interventions de longue durée sous anesthésie balancée. Les sujets de l'étude sont ágés de 50 à 70 ans et ne souffrent pas de maladie neuromusculaires. Les patients due groupe ATR reçoivent une dose d'attaque de $0,25 \mathrm{mg} \cdot \mathrm{kg}^{-1}$ suivie par une perfusion réglée au départ à $5 \mu \mathrm{g} \cdot \mathrm{kg}^{-1} \cdot \mathrm{min}^{-1}$. Dans le groupe VEC $(n=25)$, les patients reçoivent une dose d'attaque de vécuronium de $0,05 \mathrm{mg} \cdot \mathrm{kg}^{-1}$ suivie par une perfusion titrée à 1,0 $\mu \mathrm{g} \cdot \mathrm{kg}^{-1} \cdot \mathrm{min}^{-1}$. Pendant la chirugie, la perfusion est augmentée ou diminuée par paliers de $12,5 \%$ pour maintenir la suppression à 90-95\% du premier twicht $\left(T_{1}\right)$. L'évaluation de block neuromusculaire se fait par l'analyse du tracé de la réponse électromyographique (EMG) du premier interoseux dorsal de la main en réponse aux stimuli supramaximaux appliqués au nerf cubital. La durée de la perfusion est la même pour les deux groupes ( $164 \pm 42$ min pour l'ATR et $183 \pm 67$ min pour VEC). La vitesse de perfusion pour ATR (moyenne \pm ET) se situe entre 4,0 \pm 07 et $5,0 \pm 1,0 \mu \mathrm{g} \cdot \mathrm{kg}^{-1} \cdot \mathrm{min}^{-1}$. Par 
contre une baisse progressive $(P<0,05)$ de la quantité perfusée de VEC passant de 1,0 à $0,47 \pm 0,13 \mu \mathrm{g} \cdot \mathrm{kg}^{-1} \cdot \mathrm{min}^{-1}$ est observée au cours de l'étude. Le nombre d'ajustements requis pour maintenir la suppression à 90-95\% de $T_{1}$ a diminué entre la seconde et la quatrième heure de perfusion mais est similaire lorsqu'on compare les deux groupes à des moments correspondants. La vitesse de récupération du rapport du train-de-quatre $>70 \%$ après le renversement avec la néostigmine $40 \mu \mathrm{g} \cdot \mathrm{kg}^{-1}$ et l'atropine $15 \mu \mathrm{g} \cdot \mathrm{kg}^{-1}$ est identique dans les deux groupes. Nous concluons qu'une perfusion continue de vécuronium réglée pour maintenir la suppression de 90-95\% de $T_{1}$ produit une accumulation appréciable après deux heures. Par contre, l'atracurium ne montre pas cette tendance à l'accumulation pendant des perfusions continues d'une durée de deux à cinq heures. Lorsque titrées d'après la réponse, les perfusions d'atracurium et de vécuronium sont faciles à administrer et à renverser lorsque la dose de néostigmine est adéquate.

Traditionally, muscle relaxants are administered using a multiple bolus technique during general anaesthesia. However, it is well recognized that this method of drug administration is associated with "peaks and valleys" of plasma drug concentrations, and may lead to varying degrees of paralysis with time. When clinical circumstances dictate, it may be beneficial to infuse the neuromuscular blocking agent, in order to facilitate a more constant degree of muscle relaxation. Of the currently available non-depolarizing muscle relaxants, atracurium and vecuronium are the most appropriate agents for administration by infusion, and both drugs have been used effectively in this manner. ${ }^{1-10}$

Desirable features of drugs administered by continuous infusion include a minimal propensity for cumulation, and rapid termination of clinical effect upon discontinuation of the medication. Although the clinical durations of action of single equipotent doses of atracurium and vecuronium are similar, these drugs have different pharmacokinetic profiles. ${ }^{11}$ Following an initial peak, there is a rapid decay in the plasma concentration of vecuronium after a single dose of this agent, because of redistribution from central to peripheral compartments. With subsequent doses, the effects of redistribution become less important, such that the decline in plasma concentration reflects primarily the process of elimination, and not redistribution. Because the duration of action of vecuronium is substantially shorter than its elimination half-life of approximately $70 \mathrm{~min}$, it has been suggested that this neuromuscular blocking drug may accumulate with repeated boluses. ${ }^{12,13}$ These pharmacokinetic characteristics also suggest that when administered by infusion during long surgical procedures, vecuronium may become a much longer-acting drug.

In contrast to vecuronium, atracurium has a more rapid clearance rate and a smaller volume of distribution, resulting in an elimination half-life of about $20 \mathrm{~min} .{ }^{11}$ The rapid decline in plasma concentration following administration of either single or multiple boluses of atracurium is primarily due to its rapid elimination. This should result in minimal cumulation, and should be advantageous when atracurium is given as a continuous infusion. ${ }^{14} \mathrm{We}$ therefore designed a study to compare the cumulation profiles during, and the times to recovery following, continuous iv infusions of atracurium and vecuronium during long surgical procedures ( $>$ two hours). In addition, the dose requirements and ease of maintaining a stable degree of neuromuscular block (number of adjustments) for each drug were compared.

\section{Methods}

\section{Study population}

This randomized, double-blind study was conducted at two university-affiliated hospitals. Approval was obtained by the Human Experimental Procedures Committees of both institutions. After obtaining written informed consent, 50 patients between 50 and $75 \mathrm{yr}$ of age, and scheduled to undergo elective general, orthopaedic or peripheral vascular surgical procedures lasting more than two hours, were enrolled. Patients with neurological or neuromuscular disorders, or those taking drugs known to interact with muscle relaxants, were excluded. In addition, patients of ASA physical status greater than Class III, and those with a history of hepatic disease or renal dysfunction, defined as a preoperative serum creatinine $>130 \mu \mathrm{mol} \cdot \mathrm{L}^{-1}$, were not considered for entry into the study. Finally, patients with a body mass index (body weight/body surface area) $<20$ or $>30 \mathrm{~kg} \cdot \mathrm{m}^{-2}$ were also excluded.

\section{Anaesthetic technique}

Subjects were randomly allocated into two groups of 25 to receive either atracurium or vecuronium. In all other respects, clinical management was identical for the two groups. Patients received premedication with oral diazepam $0.15 \mathrm{mg} \cdot \mathrm{kg}^{-1}$ which was given $90 \mathrm{~min}$ preoperatively. In the operating room, the following monitors were attached: electrocardiogram, non-invasive blood pressure monitor, pulse oximeter, and temperature probe. During the study, inspired and end-tidal concentrations of oxygen and carbon dioxide were monitored using either mass spectrometry or infrared analysis.

All patients received droperidol $1.25 \mathrm{mg}$ iv for prevention of nausea. Alfentanil $20-30 \mu \mathrm{g} \cdot \mathrm{kg}^{-1}$ was administered over two minutes while the patient breathed $100 \% \mathrm{O}_{2}$ by mask. Loss of consciousness was induced with thiopentone $2-4 \mathrm{mg} \cdot \mathrm{kg}^{-1} \mathrm{iv}$, followed by administration of the loading dose of muscle relaxant study medication given 
from a coded syringe. Tracheal intubation was performed under direct laryngoscopy when maximal neuromuscular blockade ( $>90 \%$ ) had been established. Anaesthesia was maintained with $70 / 30 \%$ ratio $\mathrm{N}_{2} \mathrm{O} / \mathrm{O}_{2}$, while minute ventilation was adjusted to maintain the $\mathrm{PETCO}_{2}$ between 30 and $35 \mathrm{mmHg}$. Prior to skin incision, a second bolus of alfentanil $20 \mu \mathrm{g} \cdot \mathrm{kg}^{-1}$ was administered to complete the loading dose of alfentanil. In addition, a continuous infusion of alfentanil was titrated in the range of $0.5-2.0$ $\mu \mathrm{g} \cdot \mathrm{kg}^{-1} \cdot \mathrm{min}^{-1}$ as required during surgery, with supplemental boluses of $7-15 \mu \mathrm{g} \cdot \mathrm{kg}^{-1}$ given whenever heart rate and systolic blood pressure increased more than $20 \%$ above each patient's baseline values. Midazolam was also given in $1.0 \mathrm{mg}$ increments iv as necessary. Volatile inhalational agents were strictly avoided because of their potential to influence the infusion rates of atracurium and vecuronium required to maintain a given degree of neuromuscular block. Fifteen minutes before termination of surgery, infusion of alfentanil was discontinued to allow the serum concentration to decline below the threshold for spontaneous ventilation upon completion of skin closure.

\section{Muscle relaxant infusion protocol}

The loading dose and infusion rates of the muscle relaxants were selected assuming a 1:5 potency ratio for atracurium and vecuronium. The loading doses, atracurium $0.25 \mathrm{mg} \cdot \mathrm{kg}^{-1}$ or vecuronium $0.05 \mathrm{mg} \cdot \mathrm{kg}^{-1}$ were administered over one minute from a coded $20 \mathrm{ml}$ syringe, according to the randomization schedule. The corresponding infusions were delivered on a volumetric basis (in $\mathrm{ml} \cdot \mathrm{kg}^{-1} \cdot \mathrm{hr}^{-1}$ ), from a second, separately coded $60 \mathrm{ml}$ syringe, using a Baxter syringe infusion pump. Initial settings were selected to correspond with infusion rates of $5.0 \mu \mathrm{g} \cdot \mathrm{kg}^{-1} \cdot \mathrm{min}^{-1}$ and $1.0 \mu \mathrm{g} \cdot \mathrm{kg}^{-1} \cdot \mathrm{min}^{-1}$ for atracurium and vecuronium, respectively. Throughout surgery, muscle relaxant infusion rates were adjusted in increments or decrements of $12.5 \%$ of the initial infusion rates as required, to maintain $T_{1}$ suppression between 90 and $95 \%$ of control. The interval between each adjustment was no less than ten minutes, in order to allow for a period of stabilization at each new setting.

Upon completion of skin closure, the muscle relaxant infusion was discontinued, and a combination of neostigmine $40 \mu \mathrm{g} \cdot \mathrm{kg}^{-1}$ and atropine $15 \mu \mathrm{g} \cdot \mathrm{kg}^{-1}$ was given to reverse the neuromuscular block. A period of spontaneous recovery was not permitted in this study, as it was deemed essential to compare the reversal times relative to an equal depth of neuromuscular block. When the TOF ratio was $>70 \%$, the lungs were ventilated with $\mathrm{O}_{2}, 100 \%$, and the trachea was extubated when the patients were awake and breathing spontaneously. Following emergence from anaesthesia, patients were transferred to the recovery room.
TABLE I Demographic data (mean \pm SD)

\begin{tabular}{lll}
\hline & Atracurium & Vecuronium \\
\hline Patients $(n)$ & 23 & 23 \\
Sex $(\mathrm{m} / \mathrm{f})$ & $12 / 11$ & $15 / 8$ \\
Age $(\mathrm{yr})$ & $65.4 \pm 7.3$ & $65.4 \pm 6.1$ \\
Weight $(\mathrm{kg})$ & $71.0 \pm 11.9$ & $76.5 \pm 12.1$ \\
BMI $\left(\mathrm{kg} \cdot \mathrm{m}^{-2}\right)$ & $25.3 \pm 3.2$ & $26.5 \pm 3.4$ \\
ASA $(\mathrm{LII} / \mathrm{III})$ & $6 / 14 / 3$ & $3 / 15 / 5$ \\
Creatinine $\left(\mu \mathrm{mol} \cdot \mathrm{L}^{-1}\right)$ & $95.5 \pm 16.0$ & $93.2 \pm 17.0$ \\
& $(72-130)$ & $(65-139)$ \\
\hline
\end{tabular}

The demographic data. $\mathrm{BMI}=$ body mass index (body mass/body surface area); ASA = American Society of Anesthesiologists' Physical Status classification; creatinine = preoperative serum creatinine. The ranges of senum creatinine values are displayed in parentheses.

\section{Measurements}

Body temperature and end-tidal carbon dioxide values were measured throughout the study. Neuromuscular function was evaluated using an integrated compound evoked electromyogram (EMG) calibrated prior to induction of anaesthesia. Train-of-four stimuli, using impulses of $0.2 \mathrm{msec}$ duration at a frequency of $2 \mathrm{~Hz}$, were measured every $20 \mathrm{sec}$ with a Datex 221 NMT Relaxograph monitor. Supramaximal nerve stimuli were applied to the ulnar nerve using skin electrodes, and the evoked electromyogram was recorded over the first dorsal interosseous muscle. Time to onset of $90 \% \mathrm{~T}_{1}$ suppression, the number of adjustments in the rates of infusion, and the mean rates of infusion for atracurium and vecuronium required to maintain $90-95 \%$ twitch depression were recorded. The time required to recover neuromuscular function (return of train-of-four to $70 \%$ ) after discontinuation of the infusion and reversal with the anticholinesterase was also measured.

\section{Statistical analysis}

Statistical analysis was performed using Student's t test, Chi-square and repeated-measures analysis of variance where appropriate. Data are presented as mean \pm standard deviation in the text, figures and tables. Statistical significance was assumed when $P<0.05$.

\section{Results}

Fifty patients entered the study. Four patients (two in each group) were excluded, either because of technical problems with the infusion, or because of difficulties in obtaining the EMG signal. The characteristics of the two groups of patients were similar, as presented in the demographic data of Table $I$.

The mean durations of infusion for atracurium and vecuronium were $164 \pm 42$ and $183 \pm 67 \mathrm{~min}$ respectively $(P=$ NS, Table II). Throughout the study period, the first twitch heights were similar in both groups, and were 
TABLE II Infusion characteristics and reversal times (Mean \pm SD)

\begin{tabular}{lll}
\hline & $\begin{array}{l}\text { Atracurium } \\
(n=23)\end{array}$ & \multicolumn{1}{l}{$\begin{array}{l}\text { Vecuronium } \\
(n=23)\end{array}$} \\
\hline $\begin{array}{l}\text { Duration of infusion (min) } \\
\text { Rate adjustments per hour: }\end{array}$ & $164 \pm 42$ & $183 \pm 67$ \\
$\quad$ First hour $(n)$ & $3.7 \pm 1.2$ & $3.1 \pm 1.2$ \\
Second hour $(n)$ & $2.6 \pm 1.7$ & $2.3 \pm 1.7$ \\
Third hour ( $n$ ) & $1.3 \pm 1.7$ & $1.2 \pm 1.2$ \\
$>3$ hours $(n)$ & $1.7 \pm 1.8$ & $0.4 \pm 0.7$ \\
T, pre-reversal (\% control) & $6.7 \pm 3.1$ & $6.5 \pm 1.9$ \\
Reversal time (min) & $13.4 \pm 4.9$ & $14.4 \pm 8.0$ \\
& $(7.7-23.0)$ & $(5.3-33.7)$ \\
\hline
\end{tabular}

The number of adjustments per hour required to maintain $90-95 \% \mathrm{~T}_{1}$ suppression during continuous infusions of atracurium and vecuronium are presented. The levels of neuromuscular block upon ternination of the infusions were similar in the two groups, as were the times for reversal $\left(\mathrm{T}_{4}>70 \%\right)$ following administration of neostigmine and atropine. The range of times to reversal are displayed in parentheses.

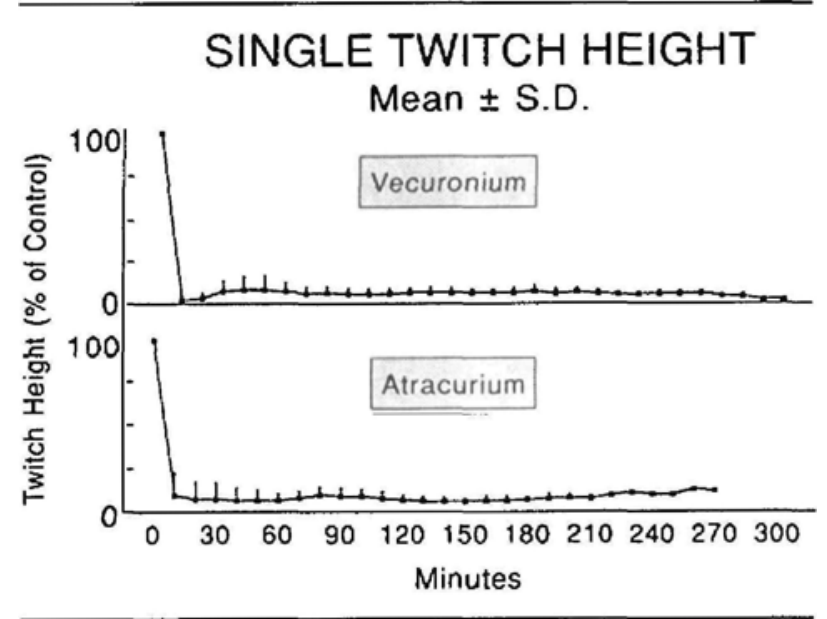

FIGURE 1 The single twitch heights (expressed as per cent of control) during continuous infusions of atracurium and vecuronium. Loading doses were administered at $t=0$ minutes. Adjustment of the infusion rates of atracurium and vecuronium allowed the depth of neuromuscular block to be maintained at a level representing $90-95 \%$ $T_{1}$ suppression throughout surgery with both neuromuscular blocking drugs.

maintained within a narrow range between 5 and $10 \%$ of control values (Figure 1). The number of infusion rate adjustments per hour required to maintain $90-95 \% \mathrm{~T}_{1}$ suppression are shown in Table II. The frequency of adjustments decreased over time for both muscle relaxant infusions, but were similar between groups at corresponding periods. At the end of the infusion, prior to reversal, the level of neuromuscular block in the two groups was also similar (Table II).

The rates of infusion required to achieve and to maintain the desired level of neuromuscular block are displayed in

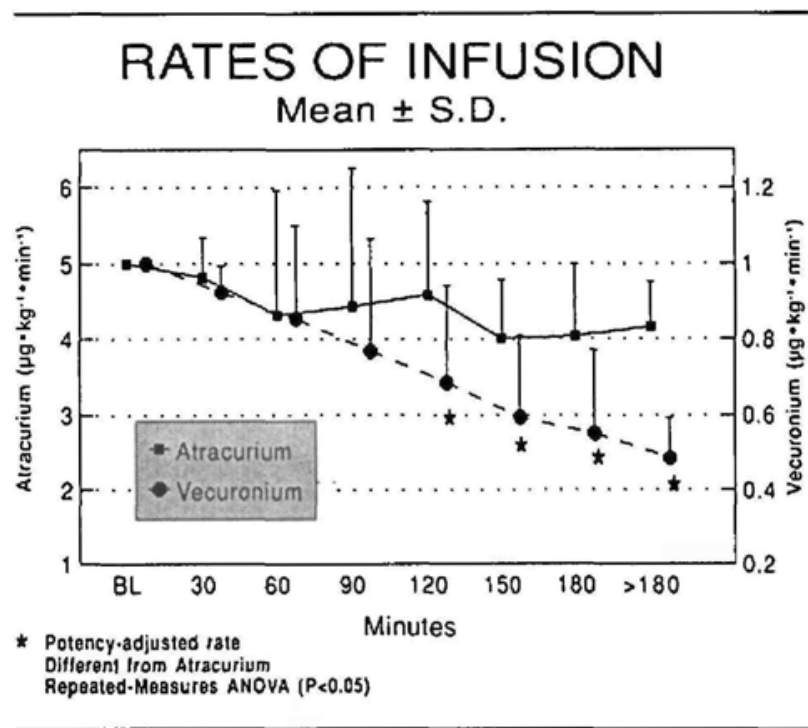

FIGURE 2 The mean infusion rates of atracurium and vecuronium required to maintain 90-95\% suppression of the single twitch height during balanced anaesthesia. A progressive decrease in vecuronium requirements from the end of the second postoperative hour demonstrates the potential for cumulation with the drug, compared with atracurium.

Figure 2. The mean infusion rate of atracurium did not vary from the initial setting of $5.0 \mu \mathrm{g} \cdot \mathrm{kg}^{-1} \cdot \mathrm{min}^{-1}$ throughout the study period. In contrast, a decrease in the infusion rate of vecuronium, from an initial setting of 1.0 $\mu \mathrm{g} \cdot \mathrm{kg}^{-1} \cdot \min ^{-1}$, was required to maintain $T_{1}$ suppression constant at $90-95 \%$. The infusion rate of vecuronium was progressively reduced after two hours, reaching a nadir of $0.47 \pm 13 \mu \mathrm{g} \cdot \mathrm{kg}^{-1} \cdot \mathrm{min}^{-1}$ by the end of surgery. The potency-adjusted (1:5, ATR:VEC) infusion rate of vecuronium was less than that of atracurium at two hours and beyond $(P<0.05)$.

Following administration of the reversal agents, return of neuromuscular function to $70 \%$ was similar in both groups (13.4 \pm 4.9 and $14.4 \pm 8.0 \mathrm{~min}$, for atracurium and vecuronium, respectively; $P=$ NS, Table II). One patient in the vecuronium group was given a second dose of neostigmine $20 \mathrm{~min}$ after the initial $40 \mu \mathrm{g} \cdot \mathrm{kg}^{-1}$, in order to attain full reversal (train-of-four ratio $>0.70$ ), which required $25 \mathrm{~min}$. In contrast, no patient in the atracurium group required a second dose of reversal agent. At the end of surgery, all patients had a normal respiratory pattern and were able to sustain a five-second head-lift.

\section{Discussion}

Since their introduction to clinical anaesthesia in the mid1980's, the use of intermediate-duration non-depolarizing neuromuscular blocking drugs has gained increasing popularity. This relates in part to the minimal side effects of atracurium and vecuronium, and also to the safety 
associated with a significantly lower incidence of residual neuromuscular blockade in the postoperative period. ${ }^{14-16}$ However, the use of atracurium and vecuronium for prolonged surgery requires frequent supplementation when using intermittent bolus methods of administration. This inevitably results in varying degrees of neuromuscular block as the concentrations of these drugs rise and fall in the plasma, and hence at effector sites in the neuromuscular junction. In contrast, administration of neuromuscular blocking drugs by continuous infusion provides for greater stability of drug concentrations, and ensures greater consistency in the degree of paralysis. ${ }^{1}$ When appropriately titrated to individual patient requirements, infusion techniques have the potential to avoid periods of both inadequate and excessive drugs effects, and may actually decrease total drug requirements while facilitating rapid reversal following administration of an appropriate antagonist.

The dose requirements and recovery characteristics following reversal of continuous infusions of atracurium and vecuronium have previously been studied. ${ }^{1-10}$ However, the tendency for cumulation and ease of reversal of these two drugs have not previously been compared in a double-blind fashion in patients undergoing long surgical procedures. This study was blinded because, although the measured end-point was both discrete and objective (twitch suppression evaluated by EMG), the criteria for adjusting the rates of infusion could have been subject to a certain degree of interpretation over the permitted infusion ranges for both atracurium and vecuronium. This fact might have biased a non-blinded observer.

Our data show that following administration of a loading dose of atracurium equivalent to $\mathrm{ED}_{95} \times 1.5$, a continuous infusion averaging between $4.0 \pm 0.7$ and 5.0 $\pm 0.8 \mu \mathrm{g} \cdot \mathrm{kg}^{-1} \cdot \mathrm{min}^{-1}$ is required to maintain the single twitch depression at a constant level between 90 and $95 \%$. In contrast, an equipotent loading dose of vecuronium followed by a continuous infusion required a progressive and significant downward adjustment in the rate of infusion to maintain the same degree of muscle relaxation. By the end of the second hour of administration, the mean rate of vecuronium infusion was $0.7 \pm 0.1 \mu \mathrm{g} \cdot \mathrm{kg}^{-1} \cdot \mathrm{min}^{-1}$, and after the third hour the mean rate had been reduced to less than $50 \%$ of the initial setting (to $0.47 \pm 0.13$ $\left.\mu \mathrm{g} \cdot \mathrm{kg}^{-1} \cdot \mathrm{min}^{-1}\right)$. The number of adjustments per hour required to maintain the $T_{1}$ suppression between 90 and $95 \%$, and the times to recover the train-of-four to $70 \%$ following administration of neostigmine and atropine, were similar for atracurium and vecuronium.

The progressive decrease in the dose requirements of vecuronium compared with atracurium can be explained by the pharmacokinetic profiles of these two agents. The elimination half-life of atracurium is $20 \mathrm{~min}$, which is approximately one-third of the 60-70 min elimination half-life reported for vecuronium. ${ }^{10,11}$ Although the patterns of clinical recovery following single doses of these two drugs are similar, recovery occurs primarily during the elimination phase for atracurium, while redistribution is more important to recovery for vecuronium. ${ }^{12}$ The terminal (elimination phase) slope of the time-concentration profile of vecuronium begins late in the first hour, after the clinical effects of the drug have dissipated. However, with larger doses or long infusions of vecuronium, the plasma concentration-time curve changes such that progressively longer times to recovery are observed. ${ }^{12}$ This phenomenon occurs to a much lesser extent with atracurium because of its shorter elimination half-life.

With repeated doses of muscle relaxants, the tendency for accumulation is manifest clinically as a slower recovery and a longer time interval required between subsequent doses in order to achieve a given degree of neuromuscular block. A continuous infusion is analogous to the administration of extremely small boluses of drug at infinitely short time intervals. Therefore, the tendency for cumulation during an infusion can be characterized by a progressive decrease in the rate of administration in order to maintain a constant effect (in this case single twitch suppression). Pharmacokinetic modelling has confirmed that cumulation is more likely to occur with infusion of longer-acting muscle relaxants such as pancuronium, whereas the tendency for cumulation is present to an intermediate degree with vecuronium, and is least with atracurium. ${ }^{12}$

Our results appear to contrast with those from Eriksson et al. which suggested that vecuronium has minimal tendency for accumulation. ${ }^{12}$ These investigators studied 15 patients undergoing operations of long duration under balanced anaesthesia, and used intermittent boluses of vecuronium to study this drug's tendency for cumulation. Following a loading dose of vecuronium $0.08 \mathrm{mg} \cdot \mathrm{kg}^{-1}$, supplemental doses $\left(0.02 \mathrm{mg} \cdot \mathrm{kg}^{-1}\right)$ were given whenever the train-of-four ratio returned to 0.25 . The duration of effect and recovery time from a TOF ratio of 0.10 to 0.25 were recorded. Despite considerable inter-individual variability, each patient had a near-constant interval between iterative doses and recovery periods for up to ten doses. This suggested little tendency for cumulation. However, a most important difference between these two studies is that the mean depth of neuromuscular blockade achieved by Erickson $e t$ al. was considerably less than the 90-95\% $T_{1}$ suppression which was achieved in our study population. It is not surprising that the propensity for cumulation depends both on the duration of drug administration, and also on the total drug mass administered over 
a given period of time. Had Erikson's group administered larger supplemental doses of vecuronium to achieve an overall mean twitch suppression of $90 \%$, they may have observed longer time intervals between subsequent doses, as sites of redistribution for vecuronium became replete.

One other factor which may account for the different findings of these two studies is that the mean age of our patient population was $65.4 \pm 6.6 \mathrm{yr}$. The pharmacokinetic behaviour of vecuronium is altered in the elderly, while the pharmacokinetic profile of atracurium is essentially unaffected by increasing age. ${ }^{19-21}$ It is conceivable that the combined influences of the relatively deep level of neuromuscular block maintained for several hours, and the greater age of the subjects in our study population, made the tendency for accumulation with vecuronium apparent during the time period which we studied. Importantly, the similarity of the preoperative serum creatinine values in the two study groups precludes the possibility that alteration of renal function could explain the decreased requirements of vecuronium which were observed.

Despite vecuronium's tendency for cumulation, the recovery of neuromuscular activity following infusions of atracurium and vecuronium were similar after administration of neostigmine. Ratcliffe et al. had similar findings when comparing neuromuscular recovery following both short ( $<1.0 \mathrm{hr}$ ) and long ( $>2.5 \mathrm{hr}$ ) infusions of atracurium or vecuronium. ${ }^{22}$ In their study, ten minutes elapsed before edrophonium $0.5 \mathrm{mg} \cdot \mathrm{kg}^{-1}$ was given with atropine 0.6 $\mathrm{mg} \cdot \mathrm{kg}^{-1}$ for reversal. This resulted in recovery times to achieve TOF $=0.7$ of $20.7 \pm 11.6$ and $19.0 \pm 11.6$ minutes for atracurium and vecuronium, respectively. Ratcliff $e t$ al. anticipated, as did we, that with prolonged infusions of vecuronium the sites of redistribution will eventually become replete, which should lead to a longer time to recovery. This mechanism resulted in a gradual decrease in vecuronium requirements in our study. However, the degree of accumulation which we observed did not appear to influence the recovery time as long as the infusion rate was adjusted to prevent a progressive increase in the depth of neuromuscular block.

Kopman also studied recovery times following assisted reversal of non-depolarizing muscle relaxant infusions, and showed similar average recovery times after infusions of atracurium and vecuronium. ${ }^{23}$ However, two of eleven patients who received vecuronium in his study demonstrated prolonged recovery periods following reversal with edrophonium, and also failed to respond to subsequent doses of neostigmine. The durations of infusion were 2.5 $\mathrm{hr}$ in one patient and $4.3 \mathrm{hr}$ in the other. One of the patients in our study who received vecuronium also required a second dose of neostigmine. The tendency for accumulation and longer elimination half-life of vecuronium may account for this observation. That is, after long infusions (when steady-state conditions are approached), the plasma concentrations of atracurium will decrease by $50 \%$ in 20 min, compared with 60-70 min for vecuronium concentrations to decrease by the same amount. This may be reflected by increased anticholinesterase requirements, or a longer time required for recovery in some individuals.

Despite the current availability of neuromuscular blocking drugs which have pharmacokinetic profiles suitable for administration by continuous infusion, a major impediment to widespread acceptance of infusion techniques has been the awkwardness of the delivery devices available for intraoperative use. Recently, several programmable syringe infusion pumps have become available for clinical use. It is predicted that with our increased understanding of infusion pharmacokinetics, and more widespread availability of these new delivery systems, that clinical acceptance of infusion techniques will steadily increase. For operations lasting more than 60-90 minutes, the ability to provide a stable level of neuromuscular blockade which can be easily titrated according to individual patient requirements, is an important advantage compared with bolus techniques for the administration of atracurium and vecuronium.

There is one further potential and entirely unique advantage of infusing muscle relaxants which has received little attention. This is the ability of an infusion technique to maintain a constant degree of neuromuscular blockade to provide relaxation which is adequate for surgery (at around $90 \% T_{1}$ suppression), but without having the patient fully paralysed. This is an important consideration with intravenous anaesthesia because of the concern regarding the potential for intraoperative awareness, and possible recall of the surgical procedure (C. Hug, personal communication). With the wider use of total intravenous anaesthesia (TIVA), there is the potential to have patients with stable cardiovascular dynamics who are pain-free, but may later complain of awareness. If, however, the patient is not totally paralysed, he or she may be able to produce some form of movement to indicate the need for additional hypnosis or analgesia. In this way, an important method of evaluating anaesthetic "depth" can be preserved throughout the course of surgery.

In summary, we compared the relative tendencies for cumulation, and ease of reversal associated with continuous infusions of atracurium and vecuronium during long surgical operations in an older patient population. A continuous infusion of vecuronium adjusted to maintain single twitch suppression of $90-95 \%$ may result in cumulation which is clinically manifest after the second hour of administration. In contrast, atracurium does not result in cumulation during infusions lasting between two and five 
hours. Despite these differences, when titrated to individual patient response, infusions of both atracurium and vecuronium are characterized by their ease of administration, and ability to be reliably reversed with an appropriate dose of anticholinesterase agent.

\section{Acknowledgements}

The authors thank the anaesthetists, nurses and surgeons at the operating rooms of the Ottawa General and Ottawa Civic Hospitals, whose assistance and patience permitted these studies.

\section{References}

1 d'Hollander AA, Hennart DA, Barvais L, Baurin M. Administration of atracurium by infusion for long surgical procedures. Simple techniques for routine use. $\mathrm{Br} J$ Anaesth 1986; 58 (suppl 1): 56S-59S.

2 Eager BM, Flynn PJ, Hughes $R$. Iufusion of atracurium for long surgical procedures. Br J Anaesth 1984; 56 : 447-52.

3 Gramstad $L$, Lilleasen $P$. Neuromuscular blocking effects of atracurium, vecuronium and pancuronium during bolus and infusion administration. $\mathrm{Br} J$ Anaesth 1985; 57: 1052-9.

4 Madsen JV, Anderson BN, Schurizek BA, Jensen OV, $J u h l B$. Atracurium administered by infusion for long neurosurgical procedures. Br J Anaesth 1986; 58: 605-15.

5 Nilsson A, Tamsen A, Persson MP. Atracurium infusion in total intravenous anaesthesia. Acta Anaesthesiol Scand 1987; 31: 205-8.

6 Fisher DM, Canfell C, Miller RD. Stability of atracurium administered by infusion. Anesthesiology 1984; 61 : 347-8.

7 Cannon JE, Fahey MR, Castagnoli KP, et al. Continuous infusion of vecuronium: the effect of anesthetic agents. Anesthesiology 1987; 67: 503-6.

8 Newton DEF. Vecuronium - continuous infusion in general practice. Excerpta Medica Current Clinical 1983; 11: 109-14.

9 Noeldge $G$, Hinsken H, Buzello W. Comparison between continuous infusion of vecuronium and intermittent administration of pancuronium and vecuronium. $\mathrm{Br} \mathrm{J}$ Anaesth 1984; 56: 473-7.

10 Shanks $C A$, Avram MJ, Fragen RJ. Pharmacokinetics and pharmacodynamics of vecuronium administered by bolus and infusion during halothane or balanced anesthesia. Clin Pharmacol Ther 1987; 42: 459-64.

11 Shanks $C A$. Pharmacokinetics of the nondepolarizing neuromuscular relaxants applied to calculation of bolus and infusion dosage regimens. Anesthesiology 1986; 64: 72-86.

12 Fisher DM, Rosen JI. A pharmacokinetic explanation for increasing recovery time following larger or repeated doses of nondepolarizing muscle relaxants. Anesthesiology 1986; 65:286-91.

13 Beemer GH, Bjorksten AR, Crankshaw DP. Pharmacokinetics of atracurium during continuous infusion. $\mathrm{Br} \mathrm{J}$ Anaesth 1990; 65: 668-74.

14 Kong KI, Cooper GM. Recovery of neuromuscular function and postoperative morbidity following blockade by atracurium, alcuronium and vecuronium. Anaesthesia 1988; 43: 450-3.

15 Lennmarken C, Lofstrom JB. Partial curarization in the postoperative period. Acta Anaesthiol Scand 1984; 28: 260-2.

16 Bevan DR, Smith CE, Donati F. Postoperative neuromuscular blockade; a comparison of atracurium, vecuronium and pancuronium. Anesthesiology 1988; 69: $272-6$.

17 Ali HH, Savarese JJ, Basta SJ, Sunder N, Gionfriddo M. Evaluation of cumulative properties of three new nondepolarizing neuromuscular blocking drugs: BWA44U, atracurium and vecuronium. $\mathrm{Br} J$ Anaesth 1983: 107S-111S.

18 Eriksson LI, Staun P, Cederholm I, Lennmarken C, $L$ Lofstrom $J B$. Experience with vecuronium during longlasting surgery. Acta Anaesthesiol Scand 1988; 32: 619-22.

19 Kitts JB, Fisher DM, Canfell PC, et al. Pharmacokinetics and pharmacodynamics of atracurium in the elderly. Anesthesiology 1990; 72: 272-5.

20 Bell PF, Mirakhur RK, Clarke RS. Dose-response studies of atracurium, vecuronium and pancuronium in the elderly. Anaesthesia 1989; 44: 925-7.

21 Rupp SM, Castagnoli KP, Fisher DM, Miller RD. Pancuronium and vecuronium pharmacokinetics and pharmacodynamics in younger and elderly adults. Anesthesiology 1987; 67: 45-9.

22 Ratcliff A, Law Min JC, Donati F, Bevan DR. Neuromuscular recovery following short and long infusions of atracurium and vecuronium. Can J Anaesth 1991; 38: A128.

23 Kopman, $A F$. Recovery time following edrophonium and neostigmine reversal of pancuronium, atracurium and vecuronium steady-state infusions. Anesthesiology 1986; 65: 572-8. 